\title{
The Impact of Musical Texts on the Text Recall of Young Learners of English in Isfahan Junior High Schools
}

\author{
Morteza Azadi \\ English Language Department, Sheikhbahaee University, Isfahan, Iran
}

Email address:

Mortezaazadi15@yahoo.com

To cite this article:

Morteza Azadi. The Impact of Musical Texts on the Text Recall of Young Learners of English in Isfahan Junior High Schools. Education Journal. Vol. 4, No. 5, 2015, pp. 232-237. doi: 10.11648/j.edu.20150405.17

\begin{abstract}
Although music possesses a kind of power and using it has been welcomed by many students in language classrooms, it seems that they take a non-serious image of the lesson while listening to songs and they may think that it is a matter of fun. The main objective of the present study was to investigate whether learning a foreign language through musical texts (songs) can have an impact on students' text recall ability in junior high schools. The participants were 90 students who were divided into three groups; two experimental and one control. Three cloze tests (fill in the blanks) were made based on the song lyrics, to measure students' text recall. All the students took the tests after listening to the songs and text passages. After four weeks of no treatment, the same tests were taken to measure students' delayed text recall. The data were obtained by counting the total number of words that were recalled. For the analysis of data One-Way ANOVA was employed, the results of which indicated that the speech group significantly outperformed the music group for songs 1 and 2. However, delayed text recall results showed no significant difference between the two groups. This study found that music was not of much help for the students and it sometimes played a distracting role.
\end{abstract}

Keywords: Song, Text Recall, Delayed Text Recall

\section{Introduction}

Today English is taught from kindergarten up to university in Iran. Teaching English to young learners is completely different from adults since young learners have particular characteristics. Halliwell (1992: P .3) states that young children do not come to the language classroom emptyhanded. They bring with them an already well-established set of skills and characteristics which help them to learn other language.So activities chosen to be used in language classrooms should be compatible with learners' characteristics. Using songs, games, role plays etc. are some of the activities that teachers use in language classrooms to make language learning enjoyable for learners. Some researchers agree that music could serve as a mnemonic technique. Firstly, processing networks for music and language seem to share the same part of the brain (Patel, 2003). It has been viewed that this overlap between music and language networks might help memory for songs. Secondly, the hemispheric function of songs might be another explanation which supports this view. Galielmino (1986, p. 20) has stated "songs bridge the brains hemisphere, strengthening retention through a complementary function as the right hemisphere learns the melody, the left, the words". Anton (1990) found that when particular activity, an ideal learning situation is established and the most productive learning occurs (p. 1170). Finally, the surface structure of a melody may also serve as a mnemonic device to learn the lyrics (Wallace, 1994). For example, the rhythm can give cues for the lyrics structure (such as the number of syllables), based on which possible choices of words is limited and the words that can be set to the melody are chosen.

However, the advantage of learning materials through song is faded as compared to spoken condition. According to the theory of dual representation of a song's lyrics and melody (Hebert \& Peretz, 2001; Peretz, 1996; Peretz, Radeau, \& Arguin, 2004), melody and lyrics are processed and stored separately in the mind, so they represent a dual task for participants to learn both components not just one (Racette \& Peretz. 2007). Indeed, based on this model, a song, while providing a dual task, makes memorization difficult and slows at initial steps but when achieved, the trace is robust, and retrieval from long-term memory is facilitated (Calvert \& Tart, 1993; Rainey \& Larsen, 2002; Wilson, Parsons, \& Reutens, 2006). According to the theory of dual 
representation of a song's lyrics and melody, it has been argued that music interferes with verbal learning at initial steps and facilitates performance in long-term retention. Thus, the purpose of the current study was to investigate whether using songs in language classrooms lead to better performance in young learners.

\section{Review of Literature}

Music has been suggested to have a beneficial effect on the performance and cognition in humans. For example, Milliman (1982) found that playing slow music in a supermarket caused customers to walk more slowly and spend more money than when a faster music was played. In the same way, Smith (1961) found that plying music in the workplace helped to relieve boredom and tension and it was shown that key punch operators while listening to music had a positive attitude toward work and all workers wanted the music to be permanent feature in their office.

Meanwhile many psychotherapists and educators who believed in the empowering nature of music, incorporated music as pedagogical tool in language classrooms and devised a new methodology in language learning area. Attempts of creating a relaxing environment and using music in language classrooms have roots in Suggestopedia approach and Gardner's "multiple intelligence model". Suggestopedia is an unusual methodology which developed by a Bulgarian educator, Georgi Lozanove, in 1978. Baroque music, comfortable seating, cheerful room decorations and dramatic techniques are the common elements which are used in this approach to promote positive suggestion. Of the many elements which are used, the place of music is much more noticeable. Music helps learners to reach a certain level of relaxation at which the likelihood of receptivity will increase. The theory of Multiple Intelligence (MI) which was developed and elaborated by Gardner in 1993, suggests that there are a number of distinct types of intelligence or talents in individuals and the Musical/rhythmic intelligence is the fourth talent that is proposed by Gardner, based on which listening to English songs is of great value to tap into musical intelligence in order to develop learners' linguistic potential.

\subsection{Music and Aspects of Language Learning}

Music plays a significant role in motivating students to learn. According to Falioni (1993), "The addition of music to the foreign language classroom as a teaching method may be a way to focus students' attention, and produce a more committed learner" (p.104). Music can also support the development of learners' abilities in reading, listening, speaking as well as provide of opportunities for learning grammar and vocabulary (Lo \& Li 1998). Hornby (1990) says that, a song is piece of music with words that is sung. Song is a great package that bundles culture, vocabulary, listening, grammar and a host of other language skills in just a few rhymes. El- Nahhal (2011) investigated the effectiveness of using children song on developing vocabulary. The researcher adopted an experimental approach and the children song was used with the experimental group. The study indicated that there was statistically significant difference between mean scores of vocabulary test in favor of the experimental group and children song provided a good opportunity for children to develop their vocabulary. Raffiee's (2010) examined the effectiveness of using humorous song on listening comprehension and immediate and delayed recall by a group of EFL learners. This study adopted an experimental approach. The sample of the study was thirty female students in an institute in Iran. The instrument was pre-post test. The results revealed that experimental group outperformed the control group in a listening comprehension, but humorous songs effect did not make much difference between immediate and delayed recall test scores. El-Nashr (2003) also in a similar study investigated the effects of using interactive games and songs on the development of listening and speaking. The study revealed that using interactive songs had a great effect on developing students' listening skills and speaking. In a study, Mardliaytun (2007) aimed to identify whether using children songs can improve students' ability in English pronunciation and whether it is effective to use children songs to teach English pronunciation. The sample of the study was 45 students. The instruments were achievement test of sound production, questionnaire and field notes. The results revealed that using children songs can improve students' ability in English pronunciation.

\subsection{Music as a Facilitator or Interference}

There has been a large amount of research conducted on the use of music as a mnemonic device ( Hebert \& Peretz, 1997; Kilgour, Jakobson, \& Cuddy, 2000; Rainey \& Larsen, 2002; Wallace, 1994; Wolfe \& Hom, 1993). Wallace (1994) conducted four experiments and found evidence that supports the hypothesis that music facilitates the learning and recall of text and melodies can provide a great deal of information about the features of text. Rainey and Larsen (2002) also conducted two experiments testing the general hypotheses that music can act as a successful mnemonic device. The first experiment looked at the specific hypothesis that participants would learn a list of unconnected text in fewer trials when the text was set to a melody compared to when they learned the list as prose. Salcedo (2010) in line with these experiments examined the effectiveness of songs on text recall; the participants of this study were English nativespeakers students learning a foreign language, they were aged between 17 to 41 . Students' text recall was measured after listening to songs and text passages. Results showed an advantage in memory recall in favor of the music group. While in delayed text recall tests no difference was found between the music and speech groups after two weeks.

Although in many studies the advantage of sung over spoken has been shown, in some cases music was found to be of little help for text recall and the melody seemed to interfere rather than facilitate word recall. Racette and Peretz (2007) provided evidence against the belief that learning verbal materials through songs facilitate word recall. In this 
study, 36 university students, half of them musicians learned an unfamiliar song in three conditions. In the sung-sung condition, the song to be learned was sung, and the response was sung responses were both spoken. In the sung-spoken condition, the response was spoken. In the divided-spoken condition, the presented lyrics (accompanied by music) and the response were both spoken. The study showed that hearing the lyrics embedded in the melody (i.e., sung) or spoken with the melody in the background did not affect word recall. The results indicated that the text and the melody of a song have separate representations in memory, making singing a dual task to perform, at least in the first steps of learning. Sim (2008) also investigated the effect of melody on word recall. The participants were 53 undergraduate introductory psychology students. The study did not find an advantage for memory of sung over spoken sentences. And the results showed that spoken sentences were remembered better than sung sentences. In conclusion, having reviewed the above studies, we found that some studies show improved recall of text when studies as a song versus a spoken passage. e.g. (Rainy \& Larsen, 2002; Salcedo, 2010, Schon et al, Wallace, 1994). While others show no benefits of music in text recall. (e.g. Racette \& Peretz). Due to these counter intuitive findings, additional research is needed to probe into this issue. Moreover, the participants in previous studies were at college level but the presents study fills a gap in the literature by examining how songs affect text recall in young learners. In addition, regarding the fact that newly-developed and small bulk of research in the field of music and foreign language learning in Iranian literature awaits much more up-to-date studies, the present study is an attempt to add one such study to this archive.

\subsection{Research Question}

What is the impact of musical texts on the text recall of the young learners of English in Isfahan junior high schools?

\section{Methodology}

\subsection{Pilot Study}

To ensure the feasibility of the main study and identify possible drawbacks of the post tests, a pilot study was carried out in the same schools where the study was to be conducted. The participants in the pilot study were not from among the participants of the main study but were similar to the target sample. The tests were piloted on 20 students and necessary changes were made in the design of the tests.

\subsection{Participants}

In order to fulfill the requirements of the study, 90 students who were studying at the second grade in two state junior high schools in Isfahan were selected based on availability. Of the 90 students who participated in this study, 30 students were assigned to the control group and the other 60 were assigned to two experimental groups. Since no language proficiency test was used to test the students' level of language proficiency, the researcher, who was also the teacher, selected the participants based on his observation and judgment of the students' performance in the classroom. Getting involved with the students provided a valuable source of information with regard to their language proficiency for the researcher. Here, the researcher removed those students who were too weak in English.

\subsection{Materials}

For this study an audio CD including 3 songs in English was used. Copies of the song lyrics were distributed among the students before playing the songs. To test recall of the song lyrics, a cloze test (fill in the blanks) was given to the students. For the second song lyric, a Cloze Generator (software that deletes every nth word of a given text) was used to delete every seventh word while for the first and third song lyrics, the words were deleted by the researcher since the lyrics of the songs were not long enough to use a Cloze Generator. The same cloze tests were re-administered to the students four weeks later to determine their delayed recall ability.

\subsection{Song Selection}

Three songs were taken from Gooyesh song time books. The researcher gave full consideration to all aspects of the songs including their vocabulary, grammar, content. Great attention was given to factors of enjoyment and vocabulary of the songs. Although most of the words were understood by the students, there were some unfamiliar words and the researcher had to explain to them. The first song was "The House". It was enjoyable and its content was related to the lesson in the student's textbook. The second song was "Environment". It was chosen since the grammar in the song was imperative sentences and the students were familiar with these types of sentences. The third song was "Seasons and Months". It was chosen since the topic of one of the lessons in their text book was related to the months and days of the week.

\subsection{Data Collection}

Based on accessibility of participants, two comparison groups and a control group were used. The control group received no special treatments. The music group was exposed to musical texts and the speech group heard the same texts without the melody and the teacher read aloud the text for the students. A copy of the musical texts (songs) was distributed among the students during the listening activity and they were not allowed to take the copies out of the classroom. All the instructions for music and speech groups were the same except for the treatment that differed. Realia was used for both groups in order to make the meaning of some words clear and easy to understand. The difference between these two groups was that students in the music group had the opportunity to sing the songs and were guided to the repetition task, while in the speech group the teacher read the texts aloud to the students 
and were guided to repeat after him.

This study lasted for 6 weeks during which one song was used for every two weeks. The students received the listening treatment 6 times during the two weeks. At the end of each treatment the test was given to all groups to test their retention of vocabulary and grammar. The cloze tests were piloted before, and necessary changes were made. To test student's delayed recall, the same tests were administered 4 weeks later for all groups. The results were then compared and statistically analyzed.

\section{Results}

\subsection{Immediate Recall}

The hypothesis was "there are no significant differences between the means of three groups in immediate text recall". To test this hypothesis, the data obtained from the three cloze tests were analyzed.

For Song1, addressing the impact of musical text on young learners' performances, the researcher statistically analyzed the scores on the cloze test, the results of which are presented in Table 1.

Table 1. Descriptive statistics for Song 1in Immediate Recall.

\begin{tabular}{|c|c|c|c|c|c|c|}
\hline & \multirow{2}{*}{$\mathbf{N}$} & \multirow{2}{*}{ Mean } & \multirow{2}{*}{$\begin{array}{l}\text { Std. } \\
\text { Deviation }\end{array}$} & \multirow{2}{*}{$\begin{array}{l}\text { Std. } \\
\text { Error }\end{array}$} & \multicolumn{2}{|c|}{$\begin{array}{l}\text { 95\% Confidence } \\
\text { Interval for Mean }\end{array}$} \\
\hline & & & & & $\begin{array}{l}\text { Lower } \\
\text { Bound }\end{array}$ & $\begin{array}{l}\text { Upper } \\
\text { Bound }\end{array}$ \\
\hline Control & 30 & 0.8 & 0.847 & 0.155 & 0.48 & 1.12 \\
\hline Music & 30 & 6.7 & 2.215 & 0.404 & 5.87 & 7.53 \\
\hline Speech & 30 & 7.9 & 2.249 & 0.411 & 7.06 & 8.74 \\
\hline Total & 90 & 5.13 & 3.636 & 0.383 & 4.37 & 5.89 \\
\hline
\end{tabular}

As it can be seen in table 1, the mean score of speech group is higher than that of music group. To determine the significance of the difference between/within groups, the researcher employed One-Way ANOVA for statistical analysis. The $P$ value for the $F$ ratio of 121.682 was .000 , based on which it can be concluded that the groups were significantly different from one another. Therefore, the null hypothesis was rejected. To check the significance of individual group differences, Multiple Comparisons were run. The significance value of the difference between the music and speech groups was 0.041 which is smaller than 0.05 , based on which it can be concluded that the speech group significantly outperformed the music group. For Song 2, the three groups were again tested. Table 2 shows descriptive statistics of the scores for the three groups.

Table 2. Descriptive statistics for Song 2 in Immediate Recall.

\begin{tabular}{|c|c|c|c|c|c|c|}
\hline & \multirow{2}{*}{$\mathbf{N}$} & \multirow{2}{*}{ Mean } & \multirow{2}{*}{$\begin{array}{l}\text { Std. } \\
\text { Deviation }\end{array}$} & \multirow{2}{*}{$\begin{array}{l}\text { Std. } \\
\text { Error }\end{array}$} & \multicolumn{2}{|c|}{$\begin{array}{l}95 \% \text { Confidence } \\
\text { Interval for Mean }\end{array}$} \\
\hline & & & & & $\begin{array}{l}\text { Lower } \\
\text { Bound } \\
\end{array}$ & $\begin{array}{l}\text { Upper } \\
\text { Bound } \\
\end{array}$ \\
\hline Control & 30 & 1.97 & 1.497 & 0.273 & 1.41 & 2.53 \\
\hline Music & 30 & 8.57 & 2.239 & 0.409 & 7.73 & 9.4 \\
\hline Speech & 30 & 10.37 & 2.297 & 0.419 & 9.51 & 11.22 \\
\hline Total & 90 & 6.97 & 4.156 & 0.438 & 6.1 & 7.84 \\
\hline
\end{tabular}

As it can be seen in table 2, the mean score of speech group is higher than that of speech group. The ANOVA showed that the groups were significantly different from one another. Therefore, the null hypothesis was rejected ( $\mathrm{F}=$ $140.522, \mathrm{P}=0.000)$. The significance value of the difference between the music and speech groups was 0.003 , based on which it can be concluded that there was a statistically significant difference between the two groups. For Song 3 the descriptive statistics are summarized in Table 3.

Table 3. Descriptive statistics for Song 3 in Immediate Recall.

\begin{tabular}{|c|c|c|c|c|c|c|}
\hline & \multirow{2}{*}{$\mathbf{N}$} & \multirow{2}{*}{ Mean } & \multirow{2}{*}{$\begin{array}{l}\text { Std. } \\
\text { Deviation }\end{array}$} & \multirow{2}{*}{$\begin{array}{l}\text { Std. } \\
\text { Error }\end{array}$} & \multicolumn{2}{|c|}{$\begin{array}{l}95 \% \text { Confidence } \\
\text { Interval for Mean }\end{array}$} \\
\hline & & & & & $\begin{array}{l}\text { Lower } \\
\text { Bound }\end{array}$ & $\begin{array}{l}\text { Upper } \\
\text { Bound } \\
\end{array}$ \\
\hline Control & 30 & 0.67 & 0.758 & 0.138 & 0.38 & 0.95 \\
\hline Music & 30 & 5.33 & 1.668 & 0.305 & 4.71 & 5.96 \\
\hline Speech & 30 & 5.93 & 1.202 & 0.219 & 5.48 & 6.38 \\
\hline Total & 90 & 3.98 & 2.677 & 0.282 & 3.42 & 4.54 \\
\hline
\end{tabular}

As it can be seen in Table 3, the mean score of speech group is higher than that of music group. The ANOVA showed that that the groups were significantly different from one another. $(\mathrm{F}=155.861$. $\mathrm{P}=0.000)$. Therefore, the null hypothesis was rejected. The results of Multiple Comparisons shows that the significance value of the difference between the music and speech groups was 0.164 which is greater than 0.05 , based on which it can be concluded a significant difference was not found between the music and speech groups for song 3 in immediate recall.

\subsection{Delayed Recall}

To test students' delayed recall ability, the same tests were administered 4 weeks later for both music and speech groups. In all the tests, the speech group performed better than the music group. However, this difference did not reach significance. For Song 1, song 2 and song 3, the sig. value of the difference between the music and speech groups were $0.884,0.087$ and 0.937 , respectively, Based on which it can be concluded that there was not a statistically significant difference between the mean scores of the music and speech groups.

\section{Discussion}

Addressing the research question which related to the impact of musical texts on text recall of young learners, the results indicated that there was a statistically significant difference between the speech and music groups in immediate text recall tests for Songs 1 and 2. Even though a significant difference was not found for Song 3, the speech group performed better on the test. The results in delayed text recall tests indicated that the speech group performed better on all the tests than the music group, although the difference between the two groups was not statistically significant. It can be concluded that such a delay might not be enough for any of the groups to affect their recall. It can be suggested here that a longer period of time may be needed to reach a 
significant effect. One of the most significant findings of this study was that music was not of much help to the students. Indeed, it had a negative impact on their word recall.

Results of this study can be discussed from two perspectives. One can be related to the contextual situation in which the experiment was done, and another of which can be discussed from a cognitive point of view. The former, two points deserve serious consideration, students' attention to the teacher and students' familiarity with the melody. Although a common belief may exists among teachers that using songs in language classrooms can potentially lower students' anxiety, students in fact take a non serious image of the lesson and they may come to think that the purpose behind this is having fun, enjoyment and getting rid of boredom. Accordingly using songs might divert students' attention from what they really need to learn to something that is of little importance and this concern might affect their word recall adversely. As Thornbury (2001a) states attention seems to correlate highly with improved recall.

Another point regarding the contextual situation is students' familiarity with the melody. If the melody of a song is unfamiliar to the students, learning the lyric can be more demanding than learning a familiar song. In line with this notion, it has been argued that at initial steps of learning lyrics, singing does not necessarily help memorization. The effect of singing on learning during this initial phase depends on prior knowledge of the melody (Moussard, Bigand, Belleville \& Peretz, 2012).

From a cognitive point of view, the results of the study agree with the theory of dual representation of a song's lyrics and melody (Besson et al., 1998; Bonnel et al., 2001; Hébert \& Peretz, 2001\& Peretz, 1996), in which it has been said that components of a song, music and lyrics are dissociable, separable and independent of each other. Peretz (1996) claims that amusic participants can recognize highly familiar songs based on their lyrics, not on their melody. According to the theory of dual representation of a song's lyrics and melody when a song is heard, its lyrics and melody are processed and stored separately in the mind. They yield a heavy load for learners to process simultaneously lyrics and melody. Indeed, learning both components is more demanding than learning one component alone. Moreover, sometimes paying attention to one component adversely affects the other. Here it seems that paying attention to music is prioritized by the students and the text is blurred while the students are listening to the songs.

\subsection{Relation of Results to Previous Studies}

The results of the present study showed that recall was greater for the speech group. These results were similar to those of Sim's (2007) and Simmons-stern et al. (2010) who did not find an advantage for remembering songs and participants recalled words better in the spoken condition. Racette and Peretz (2007) also provided evidence in favor of the spoken condition and they showed in the sung condition fewer words were recalled. The findings of the current study do not support the results of Salcedo (2010), Rainey and
Larsen (2002) and Wallace's (1994) in which it was shown that memory recall was significantly greater with music than the spoken condition.

\subsection{Limitations of the Study}

A number of caveats need to be noted regarding the present study. First of all, lack of probability sampling prevents the researcher from generalizing the findings to other students in junior high schools. Second, the sample of the study was small; it would be better if it was done with a larger sample since the participants might not represent the majority of students in junior high schools. Third, this study identified four weeks after the treatment to measure student's delayed recall; it would have been better if the measurement was done in a prolonged period of time to have more reliable results. Fourth, the assessment of song learning through written recall might affect students' performance since it requires them to perform a different task that is somehow unfamiliar to them. Finally, since the selection of the participants was done by the researcher himself, it is undeniable that certain degrees of subjectivity might be found in the study.

\subsection{Suggestions for Future Research}

Further work needs to be done at this level to establish whether using songs in language classrooms have any effects on student's memorization of words. It is also recommended that this study be replicated with larger sample and higher levels of language proficiency. It is suggested that in order to measure students delayed recall, extending the period of time between the treatment and the final test might be of great value to determine the exact impact of songs on students' memorization of words.

\section{Conclusion}

The present study was an attempt to probe into the impact of songs on students' memorization of words. The results showed that the group in which the students listened to the songs did not perform better than the group in which no songs were played. The findings were consistent with the theory of dual code representation of songs in which music and text are processed and stored separately in mind. By this view, learning song lyrics at initial phase does not necessarily help memorization. Even though according to this theory, music has been suggested to be an aid for verbal long-term retention, which indicates that regular relearning episodes of a song increases the possibility of better verbal long term retention, the present study did not find any advantage of songs in student's long term retention of words.

\section{References}

[1] Anton, R. J. (1990). Combining singing and psychology. Hispania, 73, 1166- 1170. 
[2] Basso, A., \& Capitany, E. (1985). spared musical abilities in a conductor with global aphasia and ideomotor apraxia. Journal of neurology and neurosurgery, and psychiatry, 48: 407-412.

[3] Calvert, S. L., \& Tart, M. (1993). Song versus verbal forms for very long-term, long-term, and short-term verbatim.

[4] EL- Nahhal, M. M. (2011). The Effectiveness of Using Children Songs on Developing the Fourth Graders' English Vocabulary in Rafah Governmental Schools. Al- Azhar University-Gaza.

[5] El - Nashar N.A. (2003). "The Effectiveness of Using Interactive Games and Songs on the Development of Listening and Speaking Skills. In EFL one classroom schools in Menia, Bani Sueif and Fayom." Future of Arab Education, Vol. 9, No. 30, pp.5-39.

[6] Falioni, J. W. (1993). Music as means to enhance cultural awareness and literacy in the foreign language classroom. Mid- Atlantic journal of foreign language pedagogy,7, 98-105.

[7] Gardner, H. (1993). Multiple intelligences: The theory in practice. New York: Basic books, Inc.

[8] Guglielmino, L. M. (1986). The effective edge: using songs and music in ESL instruction. Adult literacy and basic education: 19-26.

[9] Halliwell, S. ( 1992). Teaching English in the Primary Classroom. Essex: Longman.

[10] Hébert, S., \& Peretz, I. (1997). Recognition of music in longterm memory: Are melodic and temporal patterns equal partners? Memory and Cognition, 25(4).

[11] Hébert, S. \& Peretz, I. (2001) Are text and tune of familiar songs separable by brain damage? Brain and cognition, 46(12), 169-175.

[12] Hornby, A. S. (1990). Oxford Advanced Learner's Dictionary of Current English. Oxford: Oxford University Press.

[13] Kilgour, A. R. Jakobson, L.S., \& Cuddy, L.L. (2000). Music training and rate of presentation as mediators of text and song recall. Memory \& Cognition, 28(5), 700-710.

[14] Lo, R. \& Li, H.C. (1998). Songs enhance learner involvement. English Teaching Forum, 36, 811.

[15] Lozanov, G. (1978). Suggestology and outlines of suggestodedy. London: Gordon and Breach Science Publishers, Inc.

[16] Mardliyatun,N. (2007). "Children songs as Media in Teaching English Pronunciation." Final Project. University Niageri Sermnarg.
[17] Milliman, R.E (1982) "Using background Music to Affect the Behaviour of Supermarket Shoppers". Journal of Marketing, Vol 46, pp 86-91.

[18] Moussard A., Bigand E., Belleville S., Peretz I. (2012). Music as an aid to learn new verbal information in Alzheimer's $\begin{array}{lll}\text { disease. } & \text { Music } & \text { 29, }\end{array}$ 53110.1525/mp.2012.29.5.521.

[19] Patel, A.D. (2003). Language, music, syntax, and the brain. Nature Neuroscience, 6, 674-681.

[20] Peretz, I. (1996). Can we lose memories for music? The case of music agnosia in a nonmusician. Journal of Cognitive Neuroscience, 8, 481-496.

[21] Peretz, I., Radeau, M., \& Arguin, M. (2004). Two-way interaction between music and language: evidence from priming recognition of tune and lyrics in familiar songs. Memory and Cognition, 32(1), 142-152.

[22] Racette, A., \& Peretz, I. (2007). Learning lyrics: To sing or not to sing? Memory and Cognition, 35, 242-253.

[23] Raffiee, M. (2010). The application of humorous song in EFL classrooms and its effects on listening comprehension. Journal of English Language Teaching. Vol. 3, No.4.

[24] Rainey, D. W., \& Larsen, J. D. (2002). The effect of familiar melodies on initial learning and long-term memory for unconnected text. Music Perception, 20, 173-186.

[25] Salcedo, C. S. (2010). The effects of songs in the foreign language classroom on text recall, delayed text recall and involuntary mental rehearsal. Journal of College Teaching \& Learning. Southeastern Louisiana University, Vol.7, No. 6.

[26] Sim, W. (2008). Music and word recall: the strength of familiar melodies as mnemonic devices. Department of psychology, the Ohio State University.

[27] Thornbury, S. (2001a). How to teach vocabulary Pearson Education Ltd.

[28] Wallace, W. T. (1994). Memory for music: effect of melody on recall of text. Journal of experimental psychology: Learning, Memory, and Cognition, 20, 1471-1485.

[29] Wilson, S. J., Parsons, K., \& Reutens, D. C. (2006). Preserved singing in aphasia: A case study of the efficacy of Melodic Intonation Therapy. Music Perception, 24, 23-26.

[30] Wolfe, D. E \& Hom, C. (1993). Use of melodies as structural prompts for learning and retention of sequential verbal information by preschool students. Journal of music therapy, 30(2), 100-118. 